\title{
The Story of Jennifer Susan Annistin of Waskaganish ${ }^{1}$
}

\section{Told by Jennifer Susan Annistin Written by Ruth DyckFehderau}

${ }^{2}$ Jennifer Susan Annistin of Waskaganish was a good wife and mother. She lived with her husband and three kids. During the days she worked, and then she came home in the evenings and looked after her family. She cooked dinner, she prepared lunches, she got everything ready for breakfast the next morning, and she hauled out the trash and all of her husband's empty beer cans. She helped the kids with their homework or whatever they needed. Every couple of days, she did the laundry for everyone in the house, she washed the floors and vacuumed, scrubbed the bathrooms, and cleaned the frig. She went to her kids' sport or school events and arranged family evenings with friends and weekends out in the bush. Everything that had to happen in that house, Jennifer did it. It was exhausting and she didn't enjoy all of it, but as long as she did all those things, she knew she was a good wife and mother.

In 2002, Jennifer did a 300-kilometre walk to experience what her ancestors had experienced in their long-distance treks. At the end of it, she felt sore all over and her feet ached more than they ever had before, but she also felt strong and capable of anything. Her mind was at ease. She did the walk again in 2003 and in 2004.

\footnotetext{
${ }^{1}$ Names and details in this story have been changed to protect identities.

${ }^{2}$ We are very grateful to the Cree Board of Health and Social Services of James Bay for the permission to reproduce this story here.
} 
In 2006, Jennifer was tired all the time. Tired and anxious and off. Maybe she was going through a bout of depression. Or maybe it was diabetes. Diabetes ran in her family.

"Go to the clinic," her sister said. "If it's something like high blood pressure, you'll just need a pill and you'll feel better."

Jennifer went to the clinic. The doctor took some blood and sent her home. Soon after, the clinic called her back and told her to come in right away. They had the results from her blood test and it was urgent.

She went back to the clinic, and slumped down in the chair in the exam room. She had never been so tired. The doctor came in and closed the door behind him. "Have you ever heard anything about anyone in your family having cancer?" he asked.

Jennifer thought for a while. Then she remembered her uncle. He had had leukemia, a cancer of the blood. They gave him a bone marrow transplant and that got rid of his cancer and they sent him home to recover. When he stepped off the plane at home, his community held a feast to celebrate his homecoming and the end of his cancer. There was plenty of food-moose and beaver and fish — and everyone in the whole community came up to him and gave him a big hug or shook his hand. He was a popular guy and people were happy to see him and to know he had that cancer licked. But someone who shook his hand or hugged him had a cold and passed it on to him. His cancer was gone, but his immune system wasn't very strong yet: the cold developed into a bad case of pneumonia and he died a couple of weeks after that feast.

Jennifer told all of this to the doctor, and then yawned. He listened thoughtfully. 
"I, uh, I think you might have leukemia too," he said. "We're going to send you to Montréal_-you might even get the same specialist your uncle had. But there are better medications and treatments for leukemia now than there were when he was sick. And in fact, we're going to start you on some of those medications now, before we even have all the test results back. The trick to beating leukemia, if that's what this is, is getting it in the early stages."

Jennifer started the medication. A week later the test results came back. She had exactly the same leukemia that her uncle had had. Other than exhaustion, she had felt no symptoms at all.

Jennifer's mom heard "leukemia" and thought her daughter was about to die, and cried herself to pieces. But Jennifer herself was so surprised that she just went about her days as if nothing had happened. By now she was weak and couldn't even do something as simple as wash the dishes, so her mother washed the dishes for her, and cried while she did them.

One evening Jennifer sat down and watched a movie in which the actor Mandy Moore played a girl with leukemia. While she watched the girl on screen go through the things that she was going to go through, a fountain of sadness began flowing inside of Jennifer. Sadness for her uncle who had died, sadness for herself because she might die now too, and sadness for the people who would miss her. She began to weep.

And then it was time to go to Montréal.

In Montréal, the doctors saw right away that Jennifer was very sick. They were surprised she was walking at all. But Jennifer had felt like this for a long time already and barely noticed their expressions of shock and concern. 
The oncologist, a doctor specializing in the treatment of cancer, gave her chemotherapy pills that would gradually kill the cancer in her blood. "This is something new," she said. "I wish I'd had this pill for your uncle because it would have helped him."

The treatment began working right away and that was good news. It meant that Jennifer would not need a bone marrow transplant like her uncle had had. She could even go home and take the pills every day there.

The oncologist wanted to see her each month. The problem was that Jennifer lived way up in Waskaganish. Flying down and back once a month on the Waskaganish-Nemaska-Chibougamau-Montréal milk run wasn't reasonable. A single doctor's appointment would take three days, more if the weather was bad. They decided together that her home clinic would take her blood every month and send it to the cancer clinic laboratory in Montréal where they would run a special test that detects even the smallest amount of cancer. Every third month, Jennifer would fly down and visit the oncologist in person. And every single day, without exception, she would take her chemotherapy pills. They were as important to her, the oncologist said, as insulin is to someone with severe diabetes.

Jennifer expected to get side effects from the chemotherapy. She met other people on the same treatment who had terrible nausea and spent time each day hung over the toilet bowl, vomiting. And their hair either fell out or lost its lustre and dried into something like straw. But Jennifer had no side effects at all.

Gradually, the cancer in Jennifer's blood was going away. For a while, life became less terrifying. Then, early in 2007, she began to menstruate more than she had ever menstruated before - and she had always had troubles with heavy menstruation. 
A few months later, the doctors decided to insert a specific type of IUD (intra-uterine contraceptive device) into her uterus, thinking that it might slow or minimize her monthly blood loss. She would still bleed heavily for a little while from hormonal fluctuations, they said, but then the bleeding would correct itself.

It didn't correct itself. Jennifer bled more than she had ever bled. She bled so much that the IUD passed right out of her in one of the giant clots of blood that were always coming out of her these days - and she didn't even notice it had happened until the gynecologist gave her a CT scan and discovered the device was no longer in her uterus. Usually, an IUD exiting the uterus is very painful, but Jennifer hadn't felt a thing.

And still she was bleeding. Instead of menstruating for a few days of each month, like most women do, Jennifer bled every single day for months and months and months.

In November, she visited a new doctor in the Waskaganish clinic. The doctor noted Jennifer's excessive menstruation and prescribed some pills to stop the bleeding. Jennifer talked about her leukemia and the chemotherapy medication she was taking - but the doctor didn't seem to pay attention and said again that these new pills should stop the bleeding.

Jennifer started taking the pills.

And everything got so much worse. She bled and bled and bled, more than she ever had. So much blood flowed now that she could feel it squish between her legs every time she moved. In just two days, she was white from loss of blood. 
Her sister came to her house that Saturday on her way to work. "What's wrong with you?" she asked. "You're so white you don't even look Cree anymore."

"I'm having my period and the doctor put me on these pills and they're not helping."

"Call the clinic," she said. "You of all people can't mess around with this stuff."

"It's Saturday. The clinic is closed."

"Call. There's always a nurse on call. Call the clinic."

Her sister left for work and Jennifer called the nurse. The nurse knew she was a cancer patient and told her to meet him there in thirty minutes.

With each passing minute, Jennifer felt worse. Her heartbeat was weak and fluttery and she couldn't get enough air. She had a bit of laundry to do in the thirty minutes before her meeting at the clinic and stumbled downstairs to the laundry room. But when she got there, she slumped against the washing machine. She didn't have strength even to sort laundry. She felt as if she might die in the next couple of minutes. Maybe it was her time. But if it was-she certainly didn't want to die in her laundry room.

She gathered all her strength and started the long journey upstairs, leaning heavily on the rail to pull herself up. It was every bit as difficult as the 300 kilometres she had walked years back. 
When she got upstairs, her twenty-year-old son was there. "I'm getting dressed to go to the clinic," she said. "If something happens to me in the next few minutes, call the clinic. I don't know if I can make it there.”

Her son looked at her and nodded wordlessly.

She was too weak to drive, she realized. Her sister was at work, her husband was out drinking, her parents were in the bush, and her son didn't have his driver's license. She was alone. She called her pastor and he came around and took her to the clinic.

The nurse at the clinic was shocked at the state of her and quickly arranged to med-evac her down to Val D'Or.

In Val D’Or, the gynecologist met her, also shocked. "You need a blood transfusion!" she said. "Your body is almost out of blood! What happened?"

Jennifer explained how she'd been bleeding for months-and the gynecologist interrupted: "You're a cancer patient! With blood cancer!" she said. "Why didn't they send you here right away?"

“There's a new doctor at home. I don't think she even read my file. I told her I was bleeding and she prescribed the pills. Then I talked about leukemia and chemotherapy, but she didn't seem to hear me. She just said the pills would make me stop bleeding over the weekend. I think they made me bleed more."

The gynecologist looked at the pills the Waskaganish doctor had prescribed. 
“Of course you're bleeding," she said. “These pills should never be taken by someone on chemotherapy! The doctor should have known that. And how can a doctor not read a patient file??"

"Well,” Jennifer said, "now I'm here. I thought I was going to die so this is better."

And then she fell asleep.

The gynecologist gave Jennifer a blood transfusion and did a process called dilation and curettage $(\mathrm{D} \& \mathrm{C})$, where the uterus is cleaned out, and gave her iron pills to rebuild her blood supply. Jennifer had lost a massive amount of blood. If it had taken much longer for her to get to Val D'Or, she would have bled to death. The gynecologist began to wonder if the chemotherapy wasn't making the bleeding worse. Jennifer reminded her that she had had problems with bleeding earlier in her life, before the chemotherapy, but still, the gynecologist was suspicious - and prevented Jennifer from taking the chemotherapy pills.

Jennifer began to feel a bit panicky then. The chemo was saving her life. Her oncologist had warned that she must never miss a day of chemotherapy because her cancer could quickly come back, worse than before, and she would have no hope.

Finally, she convinced the gynecologist at least to call the oncologist and talk about it.

And over the phone, the oncologist shouted exactly what Jennifer had said: "Ms. Annistin had problems with bleeding long before she had cancer! 
Obviously, her bleeding is not being caused by caused by the chemo pills—and in fact they're saving her life. Will you please get her back on those pills?!!”

The gynecologist relented. After four days without chemotherapy, Jennifer began taking her chemo pills again.

Two other things happened then: the gynecologist ran a whole bunch of tests on Jennifer. It turned out that she had a condition called adenomyosis and it had caused all the heavy bleeding. And she also gave Jennifer a note to put in her Waskaganish medical file: "URGENT: If Jennifer ever menstruates abnormally or haemorrhages in any way, or has unusual symptoms of any sort, send her straight to the gynecologist in Val D’Or."

With the new treatments, Jennifer's bleeding slowly lessened though she still bled more than she was supposed to. And slowly the cancer in her blood began to disappear. Each cancer screen looked better than the one before, until the screens came back cancer-free. Later her son said, "Remember that time you almost didn't make it to the clinic? You looked so sick I was afraid for you! I'm glad you're okay now."

Jennifer was okay-but she made a few changes at home. Even when she had been at death's door, her family had expected her to do all the housework. She could have died doing laundry.

What a way to go.

"From now on," she announced to her family, "I'm not doing anyone's personal laundry. I'm doing my own laundry and the towels for the house. If the rest of you want clean clothes, you can wash them. If you don't want to do 
laundry, then wear dirty clothes." She would always remember 2007 as the year of the haemorrhaging.

For a few beautiful months, Jennifer felt normal. She had normal levels of iron in her blood, she had normal amounts of blood, and she had normal cancer-free blood. She still bled too much, all the time, but it was at a level she could cope with.

Then she went to the doctor for a routine check-up and found out that she had diabetes. The doctor gave her some pills. So much for normal. Whatever, she thought. After cancer and haemorrhaging, diabetes isn't scary at all. Other than taking her pills regularly, she didn't pay much attention to the new diagnosis.

In 2008, Jennifer sat down and wrote a letter to the corporate sector of Waskaganish saying that she needed her own place. She didn't write a word about her health problems-not the bleeding, not the leukemia, not the diabetes. A friend read the application before she sent it in.

"Jennifer," she said, "maybe you should tell them about your health problems. Tell them the cancer might come back and how hard it is to deal with. Tell them that you need your own space if you're going to be healthy. Be honest."

It wasn't a comfortable thing to write. Jennifer didn't want to think of herself as a person with more needs than other people. She didn't like speaking badly of anyone, even if it was just that her husband wasn't there for her when she needed help, or that in their home no one looked after her when she was sick. She didn't want people to pity her, she didn't like to sound like she was complaining, and she especially didn't want to think of herself as someone who would turn her back on a marriage. Writing those things made her feel guilty. 
But in the end, she took her friend's advice and re-wrote the application. She wrote frankly about her year of cancer and about her year of haemorrhaging and how she needed space and time to herself for healing. She wrote that her cancer might come back, and, if it did, she would need reliable people around and a home where she didn't have to worry about running a complicated household or about the troubles surrounding a husband who hadn't yet confronted his addictions. Her doctor in Waskaganish also wrote a letter of support, and a nurse who knew Jennifer's background talked to her and showed her that moving to her own home to look after herself was the right thing to do. Her friends and parents supported her, her kids were grown and didn't need her at home anymore, her son said he just wanted her to be happy and knew his dad had no plans to stop drinking. Even her pastor supported her decision. At first the council was reluctant to give her housing: they thought that she and her husband were just squabbling like any longmarried couple, would soon mend their relationship, and she would want to stay where she was. But they changed their minds and one day she received a letter that a house was being built for her. In 2010, she could move in.

Jennifer spoke to her husband then, gave him two years to clean up his act, and said she would leave if he didn't. He tried, for a while. But addictions are powerful and his drinking won out again.

In 2010, Jennifer left his house and moved into her own place.

As she was out shopping, buying her own pots and pans and towels and sheets, she thought about guilt. Once, she had believed that two married people have to stick together no matter what. Once, she had believed that good moms didn't have their own lives: everything they did was for their families. They would put up with anything at all from their families and would do everything possible to make them look good. Once, she would have been wracked with guilt just for thinking about looking after herself. Cancer had 
changed all of that. She had to look after herself. No one else was going to do it. She knew that now. It was a good change.

When she moved into her own place, she felt neither guilt over her choice nor anger with anyone. Only peace. Plenty of peace.

Jennifer loved her new home, and her health began to improve noticeably now that, for the first time in her adult life, she could focus on herself. Her granddaughter moved in with her to keep her company, she still had plenty of contact with her kids and other grandkids, and she was able to be more involved in the community. The cancer stayed where it belonged (in remission and not in her body) and she didn't pay too much attention to the diabetes. But still, she was bleeding. She had been menstruating non-stop now for about five years. It was inconvenient, expensive, and annoying. And kind of amazing that a person could bleed for that long and not die.

In March of 2012, without warning, it began to storm-and Jennifer began haemorrhaging again. Outside snow fell by the bucket, and inside it felt like blood was pouring out of her by the bucket.

This time, she didn't hesitate. She went straight to the clinic. The doctor there called the gynecologist in Val D'Or, and explained what was happening. Then she turned to Jennifer.

“They want you in Val D’Or right away."

They both looked out the window. The storm was getting worse. Snowdrifts were piling up under the clinic windows and cars on the road had slowed to a crawl. 
Still, Jennifer went to the airport. The winds were too strong for planes to land, the airline worker said. There would be no flights today.

Jennifer called the clinic. "I'm going to have to drive there," she said.

“The weather's insane! You can’t drive."

"If I wait, I'm either gonna go into shock or lose so much blood I might die-you know this. It's less risky for me to drive. I have to take care of myself. I'll call you when I get there." She called her ex then and he offered to drive her to Val D'Or so she wouldn't have to go alone.

Now she hurried. Her ex fueled up the car, she grabbed an armful of extra pads to absorb the blood flowing out of her, and they drove as quickly as the roads allowed from Waskaganish all the way down to Val D'Or. In the storm, the trip took two hours longer than it usually would, and by the time she got there, she had that old familiar weakness from loss of blood.

In Val D'Or they were waiting for her. They had scheduled her surgery a few days later, but, when they saw her, they gave her papers to sign and wheeled her into surgery right away. Jennifer didn't even have time to call the clinic in Waskaganish and tell them what was happening.

Again the surgeon did the D\&C procedure and everything worked out nicely. They gave her a hormone injection to help control the bleeding, and said she would have to get one of these injections every three months. When her strength came back again, Jennifer and her ex drove back home. 
At first, it seemed like the shots weren't doing anything, but then Jennifer started bleeding less and less, until her menstrual cycle finally, after all those years, became normal again.

The time had come for Jennifer to focus on her diabetes. For a long time, her other health problems had seemed so much more pressing that she hadn't given it much thought. But then a doctor told her that diabetes is as lethal as cancer. If she didn't take it seriously, it would finish the job that cancer started. After all the effort she had put into building a healthy life for herself, a life where she mattered, it didn't make sense to ignore diabetes.

She was already eating carefully to help her body fight the cancer and the bleeding, but she met with a nutritionist nonetheless, and made a few more changes in her diet. She also began to measure her blood sugar levels regularly and to take insulin. The doctor said she should walk. That was a bit frightening. When she had been so sick with cancer or haemorrhaging, she had forced herself into physical activity and had collapsed from exhaustion. Still, she gave walking a thirty-minute try.

It felt okay. Good even. It reminded her of those long long walks she had done ten years earlier. Maybe she would work up to one of them again.

It had been a long journey and a difficult decade. And what she had learned most of all was that the key to good health-physical and emotional and spiritual—was looking after herself with as much care and diligence as she had once looked after others. For the people who loved her and wanted her to stick around, it was the most important thing she could do. 